\title{
Oesophageal cancer and alcoholic spirits in central Africa
}

\author{
N. D. McGLASHAN \\ From the Department of Geography, University of Zambia, Lusaka, Zambia
}

SUMMARY A geographical pathology survey of a large area in central Africa is described and a contrast is recognized between neighbouring areas with apparently many and apparently few cases of oesophageal cancer. This distribution is compared first with other known areas of high and low incidence in sub-Saharan Africa and then with the drinking of indigenous types of distilled spirits. A significant order of spatial correlation is shown between the geographical pattern of the disease and the drinking of sugar-based alcoholic spirit in central Africa. Samples of spirits from eastern Zambia, central Kenya, and the Transkei, although prepared in apparently dissimilar utensils, were all shown to be contaminated in varying degree with zinc. Nitrosamine-like compounds in native spirits were also reported in all these areas.

The need for a geographical survey of indigenous drinking habits in Africa is illustrated. Since legislation against distilling is ineffective, a simple means of excluding carcinogenic compounds from illicit spirits should be ascertained and widely promulgated at village level.

For several years it has been recognized that carcinoma of the oesophagus has a remarkable geographical distribution in Africa. Recent reports (Ahmed, 1966; McGlashan, 1967; Oëttlé, 1963a) emphasize the difference of incidence in qualitative terms but data have usually been collected only for small areas, often a region familiar to one medical officer, and it is rare to find numbers of cases related to the population at risk to allow quantitative comparison with other areas.

Statistical data of the type described by Doll (1967) are not available for most of Africa and are unlikely to be produced for another generation. The purpose of this paper is to show that less rigorous methods can yield results of value in geographical pathology. Indeed, if epidemiological information cannot be extracted from today's diverse types of data, valuable opportunities will be lost because African social systems are changing and will gradually approach the customs of more advanced peoples. (An example of this type of change is the geographical spread in Africa of the cigarette at the expense of both snuff taking and the 'hubble-bubble' (water) pipe formerly indigenous over wide areas.)

GEOGRAPHICAL PATHOLOGY IN CENTRAL AFRICA

During 1966 and 1967 a geographical survey of the distribution of certain selected diseases, which in- cluded five specific sites of cancer, was carried out from the University of Zambia. The area covered all hospitals of the ex-Federation of Central Africa, the province of Katanga in the Congo (Kinshasa) Republic, and the Tete district of Portugal's Mozambique province (Fig. 1). Additional questions on socio-environmental variables were asked only in Zambia, Malawi, and Katanga.

The method used was that introduced by Palmer (1963) with slight local modifications. I paid a visit to every hospital and, following a standardized form, asked each hospital superintendent (or his staff) by recall of cases how many cases of each disease were seen in an average year. The numbers given were classed on a geometrically increasing scale. Inaccuracies arise from possible uncertainties of the original diagnosis since histological proof is the exception in central Africa. Memory must also be sometimes inaccurate, probably affecting figures for cancer less than for other diseases because of cancer's more dramatic mental impact. Data on populations at risk were not available and there are no estimates on the proportion of the sick who do not report for western-type medicine.

The method, because of its weaknesses, is therefore only expected to show broad trends of distributional difference. Of the 55 diseases surveyed, oesophageal cancer was the most geographically interesting (Fig. 2). Figure 2 originally showed the class of each 


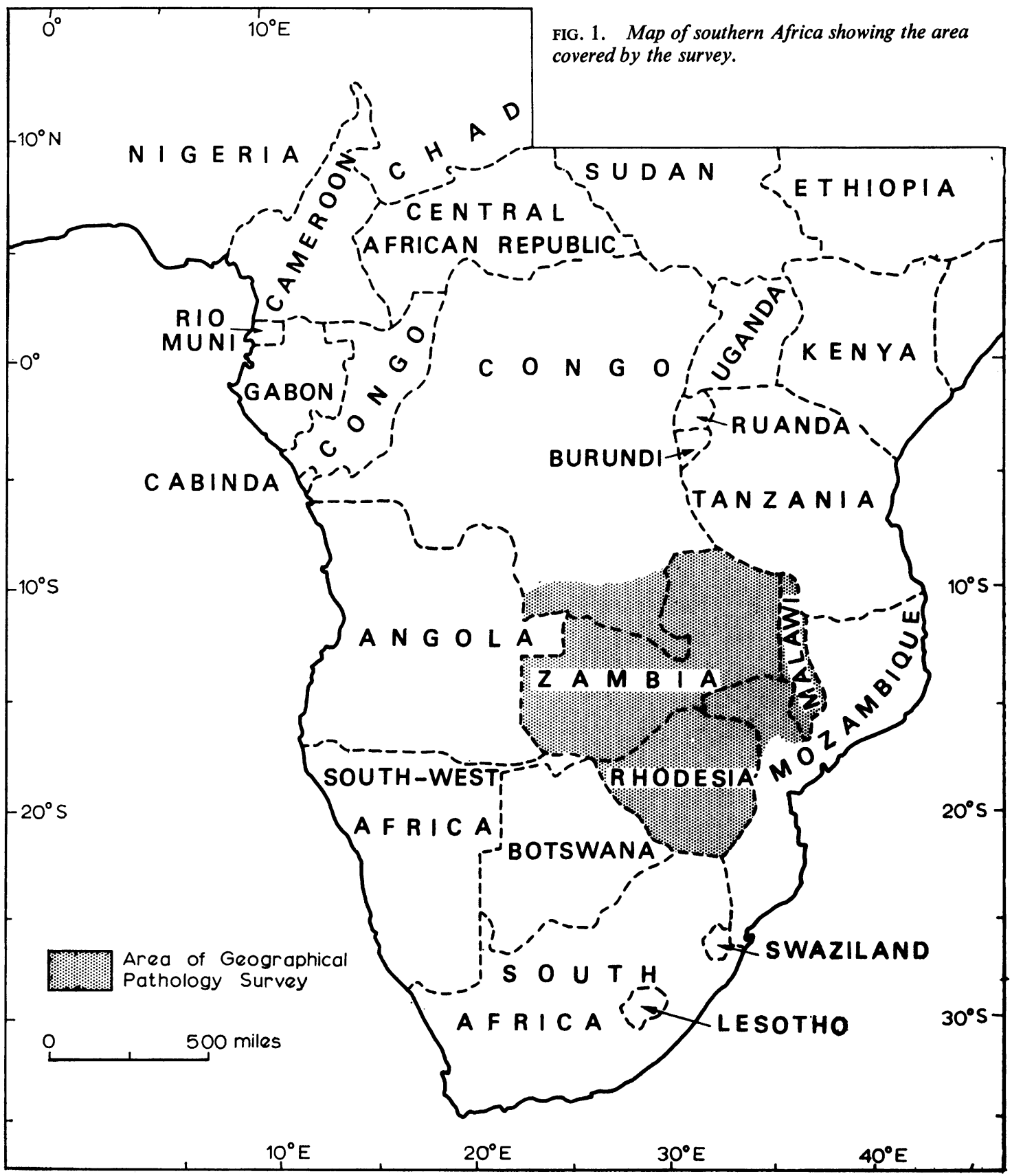

hospital's report of its cases seen. That has been generalized here to draw attention to the main area of high numbers of cases. This lies in eastern Zambia and Malawi, leaving Katanga and northern and western Zambia almost without a case within the period of recall of the present medical officers.

Within Zambia itself a further check was carried out by inspection of the records of the three main hospitals which receive referred patients, namely, Lusaka, Kabwe, and Kitwe. These three hospitals were consulted about the place of origin of all their recorded oesophageal cancer patients for the years 1965 and 1966. Two difficulties immediately arose. Even in these major government hospitals only 


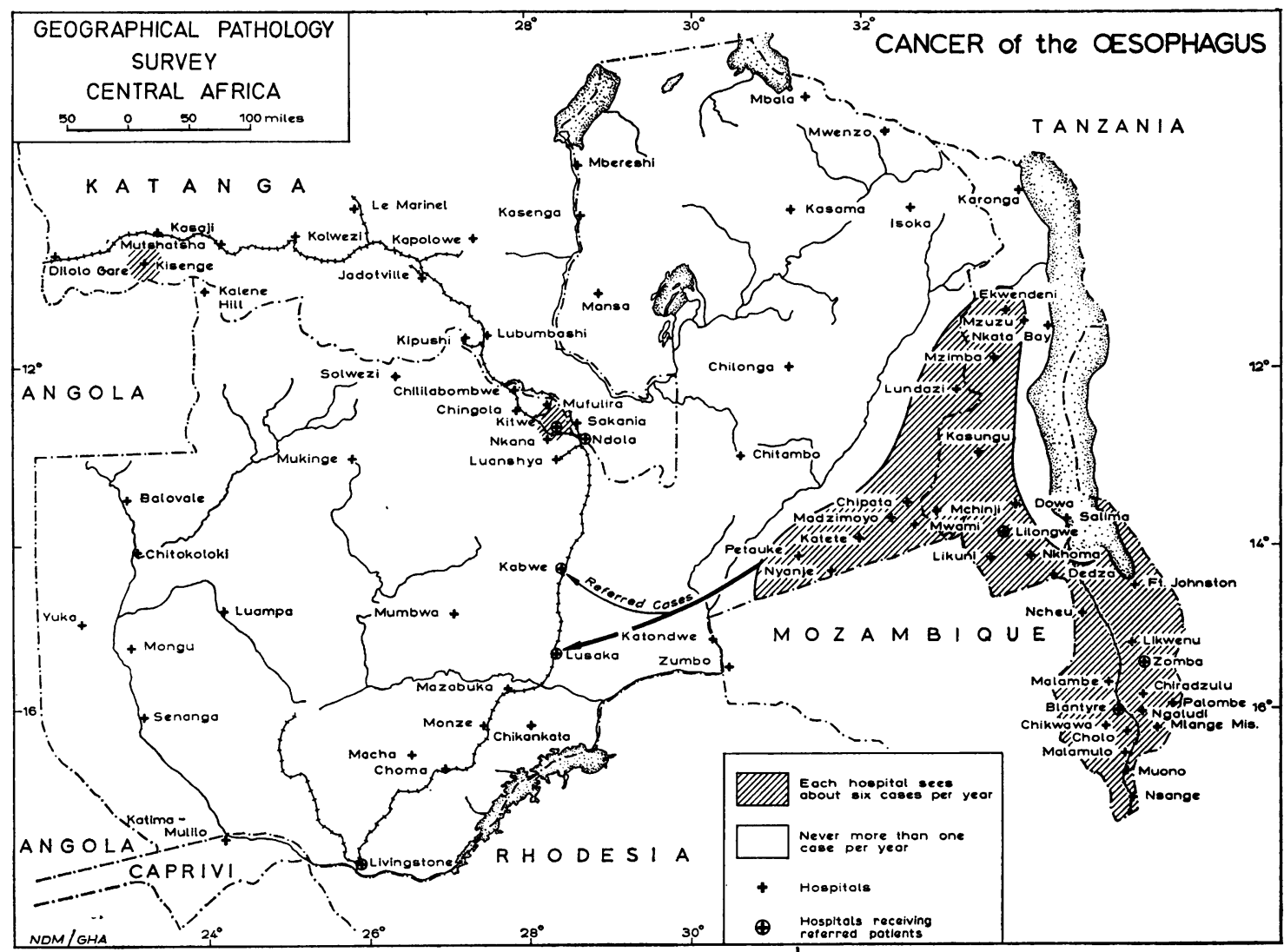

FIG. 2. Map showing the area of highest incidence of cancer of the oesophagus.

incomplete records could be unearthed. There seems, however, to be no reason to consider that lost records would be predominantly of any particular type of patient or that this would introduce bias to the remaining records. The second difficulty was that the 'home' recorded on a patient's card may bear little reference to where he has actually lived and been at risk of oesophageal cancer.

The recorded cases have been tabulated to show what percentage come from the eastern province. (Table I).

\section{TABLE I}

RECORDS OF OESOPHAGEAL CANCER IN ZAMBIAN HOSPITALS RECEIVING REFERRED PATIENTS IN 1965 AND 1966

\begin{tabular}{llll} 
Hospital & No. of Reports & $\begin{array}{l}\text { No. from } \\
\text { Eastern Province }\end{array}$ & $\begin{array}{l}\text { Percentage from } \\
\text { Eastern Province }\end{array}$ \\
\hline
\end{tabular}

\begin{tabular}{lrrl}
\hline Kitwe & 4 & 0 & 0 \\
Kabwe & 6 & 2 & 33 \\
Lusaka & 25 & 8 & 32 \\
Total & 35 & 10 & 28.6
\end{tabular}

The 1963 census for Zambia (Northern Rhodesia) gave the population of the eastern province as $14.2 \%$ of the total population of Zambia. Thus it appears, on admittedly inadequate statistics, that $28.6 \%$ of referred oesophageal cancer patients are drawn from only $14 \%$ of Zambia's population. This is mentioned merely as evidence slightly corroborative of Figure 2. There is no significant geographical variation in the age structure of the rural population, and that could not be the explanation for variations in the incidence of cancer.

The effect of the discovery of this pattern is to place eastern Zambia and Malawi among the 'black spots' for oesophageal cancer already recognized in Africa (Oëttlé, 1963b). Additionally this distribution map puts western and northern Zambia, with contiguous south-western Tanzania, among the areas with exceptionally few cases (Fig. 3).

The implications of the distribution of oesophageal cancer in southern Africa shown in Fig. 3 are puzzling. It is difficult to postulate any factor of 


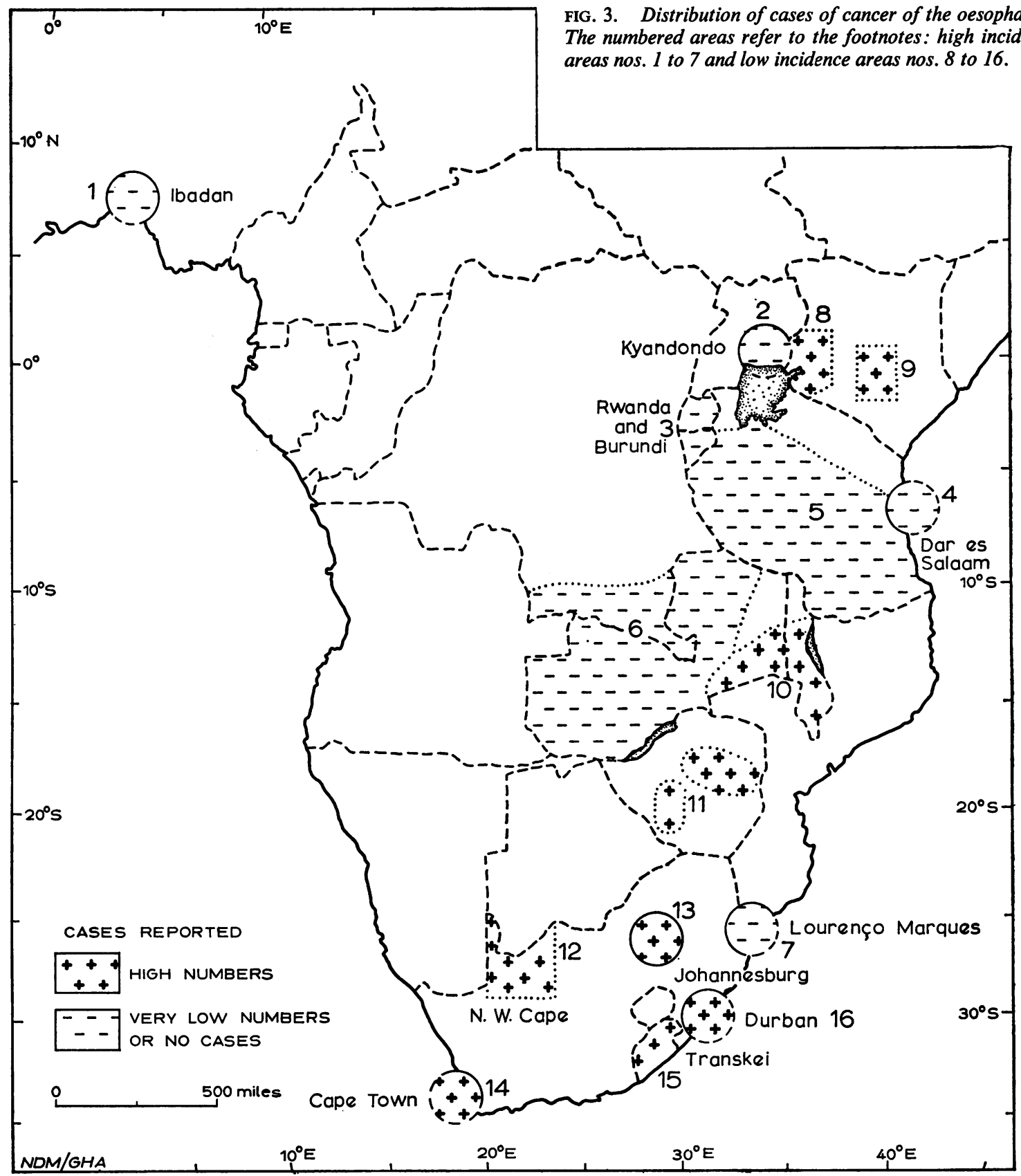

${ }^{1}$ Ibadan, Nigeria. Doll, R. (1967). Prevention of Cancer: Pointers from Epidemiology. Nuffield Provincial Hospitals Trust, London.

'Kyandondo, Uganda. Burkitt, D. P., Nelson, C. L., and Williams, E. H. (1963). Some geographical variations in disease pattern in East and Central Africa. E. Afr. med. J., 40, 1-6.

${ }^{8}$ Rwanda and Burundi. Burkitt, D. P. (1967). Personal Communication.

-Dar-es-Salaam, Tanzania. Doll, R. (1967). Prevention of Cancer: Pointers from Epidemiology. Nuffield Provincial Hospitals Trust, London.

${ }^{5}$ South-west Tanzania. Palmer, P. E. S., and McGlashan, N. D. (1965). Unpublished papers, South African Institute for Medical Research.

'North and West Zambia and Katanga. McGlashan, N. D. (1967). Lancet, 1, 578 and Bie, P. de, and Delville, J. P. (1950). Cancer et bilharziose hépatiques au Katanga. Ann. Soc. belge Méd. trop., 30, 1423.

'Lourenco Marques, Mozambique. Prates, M. D. (1958). Malignant neoplasms in Mozambique. Brit. J. Cancer, 12, 177-194.

${ }^{8}$ North-west Kenya. Ahmed, N. (1966). Geographical incidence of oesophageal cancer in West Kenya. E. Afr. med. J., 43, 235-248.

${ }^{\circ}$ Central Province, Kenya. Palmer, P. E. S., and McGlashan, N. D. (1965). Unpublished papers, South African Institute for Medical Research.

${ }^{10}$ Malawi and Eastern Province, Zambia. McGlashan, N. D. (1967) Zinc and oesophageal cancer. Lancet, 1, 578.

${ }^{11}$ Central Rhodesia. Ibid.

${ }^{12}$ North-west Cape Province, South Africa. Oettle, A. G. (1963). The frequency of oesophageal cancer among the Bantu attending hospitals. Med. Proc., 9, 78.

${ }^{13}$ Johannesburg. Oettle, A. G. (1963). Regional variations in the frequency of Bantu oesophageal cancer cases admitted to hospitals in South Africa. S. Afr. med. J., 37, 434-439.

${ }^{14}$ Capetown. Ibid.

${ }^{15}$ Transkei, Burrell, R. J. W. (1962). Esophageal cancer among Bantu in the Transkei. J. nat. Cancer Inst., 28, 495-514.

${ }^{16}$ Durban. Schonland, M., and Bradshaw, E. (1968). Cancer in the Natal African and Indian, 1964-66. Int.J. Cancer, 3, 304-316. 


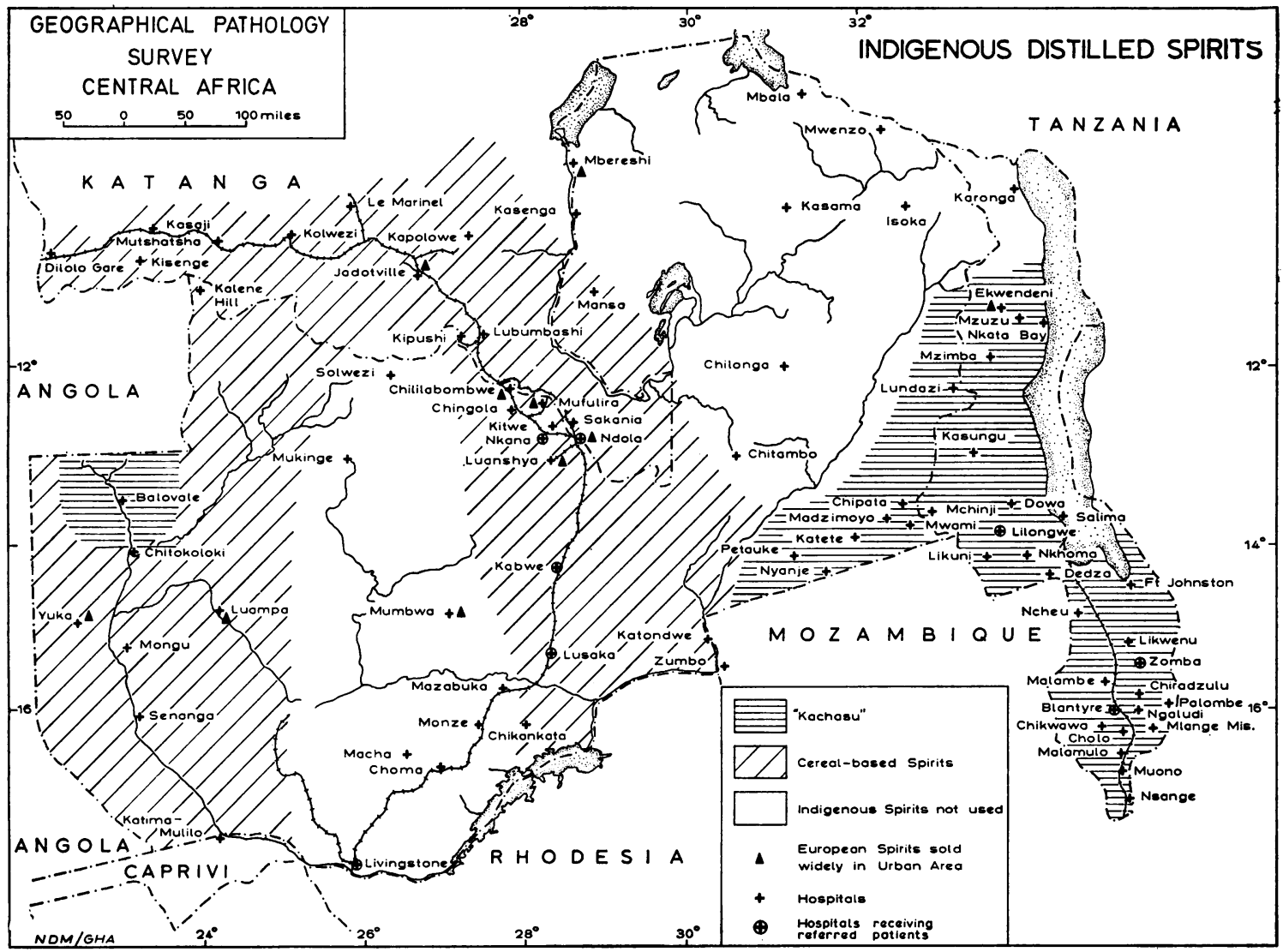

FIG. 4. Map showing the different types of distilled spirits in general use in the area of survey.

physical environment which might equally affect all the areas with high numbers of cases. Certainly they are not all areas of deficient soil or poor crops as suggested by the Transkei workers (Burrell, Roach, and Shadwell, 1966). They also vary widely in altitude above sea level, in rainfall, and in temperature ranges.

Since it appears that an environmental factor is predominant (Steiner, 1954), it may be that social rather than physical environment should be studied. Certain social customs may be proved to have a widespread and yet irregular distribution. For this reason, and following existing suggestions (Doll, 1967; Burrell, 1962), standard questions were designed for the central Africa survey concerning the local use of tobacco and the local types of beverage and distilled spirits. The answers about tobacco and beers were mapped and yielded no significant result. The map of types of distilled spirits in general use around each hospital is given in Figure 4.

Inspection by eye makes it appear that the oesophageal cancer areas shown in Fig. 2 and the Kachasu drinking areas in Fig. 4 are coextensive. Kachasu distillation is based upon a beer brewed from sugar and maize husks fermented together and is to be distinguished from cereal-based spirits where whole grain is used without sugar. The chi-squared test applied to the hospital reports confirms this impression and the results are tabulated in Table II,

\section{TABLE II}

OESOPHAGEAL CANCER AND SPIRIT DRINKING IN TWO HOSPITALS

No. of Oesophageal Cancer Cases per Annum

Nil Under 2 2 to 51 Total

$\begin{array}{llllll}\text { Kachasu drinking } & 3(19 \%) & 4(25 \%) & 9(56 \%) & 16 & \text { Ob- }\end{array}$

Other or no spirits $21(60 \%) \quad 9(26 \%) \quad 5(14 \%) \quad 35\}$ served

Total

24

Kachasu drinking $\quad 7.5$ Other or no spirits 16.5 13
$4 \cdot 1$ 14

Total

24

13

$4 \cdot 4$
$9 \cdot 6$
6 Ex-

$n($ degrees of freedom $)=2 ; \chi^{2}=11 ; \quad P=0.005$ 


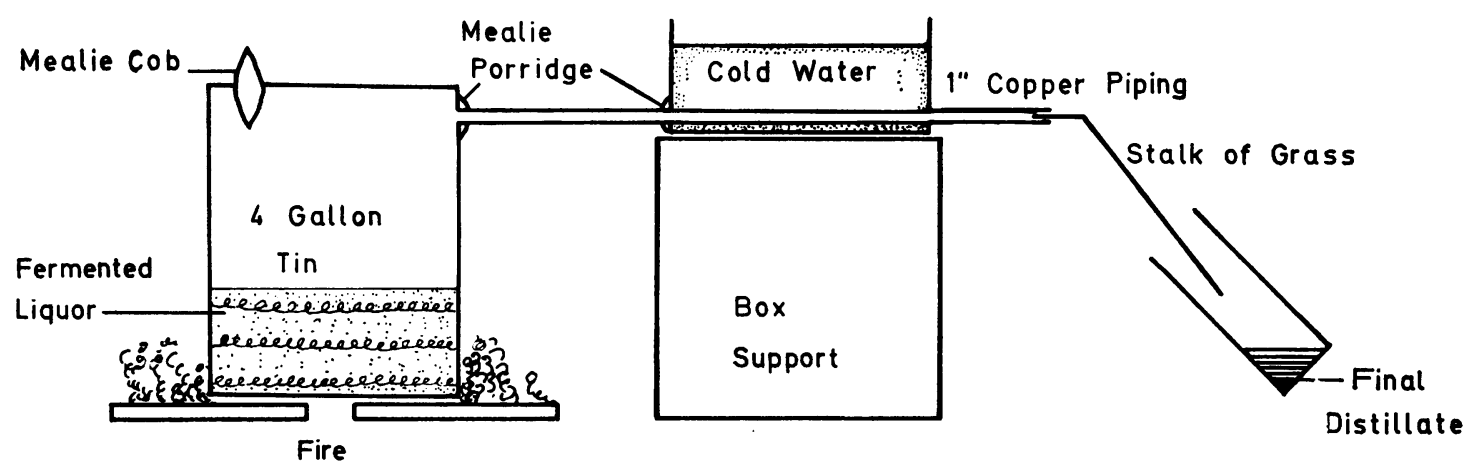

FIG. 5. Diagram of the equipment used for distilling kachasu.

where the numbers in each column represent hospitals. Because each report refers to the general custom around the hospital, reports from hospitals serving multitribal areas, such as mining and administrative centres, where no generalized answer is possible, have been excluded from the statistical test. The test result $(P=0.005)$ suggests that this association of disease and drinking custom would occur by random chance only once in 200 times.

Similar tests suggest that oesophageal cancer is significantly absent from the areas in this survey in Zambia's northern province where millet beer is drunk and also that it is significantly commoner where maize rather than cassava (manioc) is the staple diet of the people. These similarities of geographical pattern may also indicate some causative link. In further investigations one might pursue the aflatoxin carcinogenesis hypothesis or question whether prepared maize lacks something which is vital to the development of normal healthy cells (Palmer, 1967).

\section{THE INDIGENOUS DISTILLED SPIRIT}

The hypothesis reported is that kachasu contains carcinogenic properties site specific to oesophageal tissue.

TABLE III

METALLIC IONS IN DISTILLED SPIRITS

$$
\begin{aligned}
& \text { No. of Zinc }(m g / l .) \quad \text { Copper }(m g / l .) \\
& \text { Samples }
\end{aligned}
$$

\begin{tabular}{|c|c|c|c|}
\hline \multicolumn{4}{|l|}{ Zambia } \\
\hline $\begin{array}{l}\text { Chipata district } \\
\text { Balovale district }\end{array}$ & $\begin{array}{r}12 \\
7\end{array}$ & $\begin{array}{r}\text { Trace }-30.9 \\
0-22.633\end{array}$ & $\begin{array}{l}0-25 \cdot 4 \\
\cdot 3-40\end{array}$ \\
\hline Malawi & & & \\
\hline $\begin{array}{l}\text { South and central } \\
\text { South Africa }\end{array}$ & 29 & $0-4.9$ & $0-28$ \\
\hline $\begin{array}{l}\text { Transkei } \\
\text { Kenya }\end{array}$ & 9 & Trace -3.6 & - Trace \\
\hline Central province & 4 & $0.5-6.2$ & 0 - Trace \\
\hline
\end{tabular}

Specimens of kachasu from eastern Zambia and spirits from South Africa and Kenya were collected in the field and, without prior treatment, were analysed by atomic absorption spectrophotometer (Unicam model SP 900A) for metal content. These analyses gave the results shown in Table III, but no iron, lead, or tin was found. The enormous range of zinc and copper values is to be expected from the variety of utensils used. The fact that in Zambia, as well as in South Africa and Kenya, these stills are illicit makes it more difficult to conduct enquiries. In Malawi this form of distilling has been permitted only since independence.

These results were followed by a further field trip to Chipata to study the method of distillation and to ascertain whether metallic ions would also be present if the distillation process were carried out in glass apparatus.

The equipment used for distilling kachasu in Zambia and Malawi is illustrated in Fig. 5, but the types and sizes of drums in use vary widely. The distilling tubes may be any one of a number of tubular utensils: old bicycle frames, gun barrels, car exhaust pipes, electric conduit, or water pipes. The equipment used for distilling Transkei gaveen looks radically different (Fig. 6). The enamel bowl condensing surface is corroded through and replaced 'about every two months'. A similar bowl dissolved in hydrochloric acid has been shown to contain $53.3 \mathrm{mg}$ of zinc per litre and $3.4 \mathrm{mg}$ of copper. Commercial (European-type) brandy, whisky, and gin showed no measurable amounts of zinc or copper using the same spectrophotometric method.

\section{THE METHOD OF PREPARING KACHASU}

The description which follows was obtained by visits to four illicit stills near Chipata. The method was 


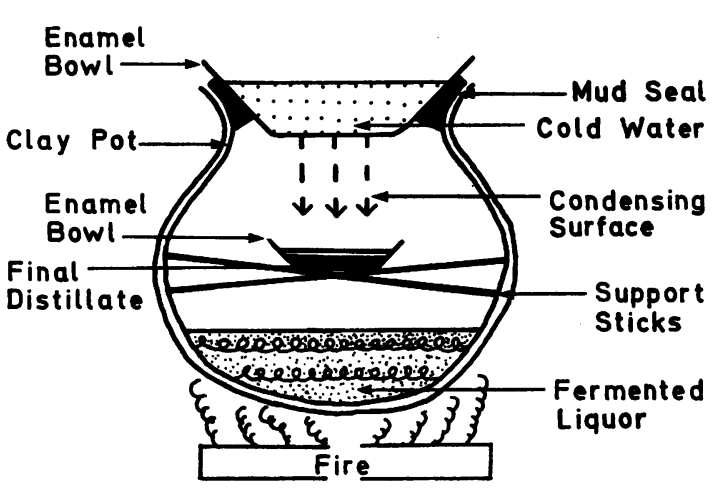

FIG. 6. Equipment used for distilling Transkei gaveen.

common to all but slight variations are made in the individual flavouring recipes which, like Drambuie, are closely guarded personal secrets.

In each case the first stage is the brewing of beer, preferably in a galvanized 44-gallon drum. Clay pots of about three gallons capacity, as used in the past, are still sometimes used but are less convenient. Maize (mealie) husks are either soaked or boiled in water and then allowed to stand for about three days. Sugar is then added and a further day or two allowed for fermentation. Immediately before distilling certain secret herbal ingredients are sometimes added. Distillation is carried out in the apparatus shown in Figure 5. The undistilled brew may be topped up from new beer up to three times during distillation. After that it is discarded as waste dregs. The highest zinc content was regularly found in these dregs (Table IV).

TABLE IV

ANALYSES FROM FOUR DISTILLERIES NEAR CHIPATA

\begin{tabular}{|c|c|c|c|c|}
\hline & $\begin{array}{l}\text { No. of } \\
\text { Samples }\end{array}$ & $\begin{array}{l}\text { Zinc } \\
(m g / l)\end{array}$ & $\begin{array}{l}\text { Copper } \\
(m g / l)\end{array}$ & Comment \\
\hline 1 Water & 3 & $0.65-1.7$ & Trace & $\begin{array}{l}\text { Local supply } \\
\text { used }\end{array}$ \\
\hline 2 Soil & 1 & $9 \cdot 8$ & $35 \cdot 5$ & $\begin{array}{l}\text { Diluted with } \\
\text { acid about } \\
1 \mathrm{~g} / \mathrm{l} \mathrm{ml}\end{array}$ \\
\hline $\begin{array}{l}3 \text { Beer }{ }^{1} \\
4 \text { Distillate }\end{array}$ & $\begin{array}{l}4 \\
6\end{array}$ & $\begin{array}{r}14 \cdot 4-25 \cdot 0 \\
5 \cdot 2-30 \cdot 9\end{array}$ & - & $\begin{array}{l}\text { Pre-distilling } \\
\text { Indigenous } \\
\text { equipment }\end{array}$ \\
\hline $\begin{array}{l}5 \text { Waste dregs } \\
6 \text { Distillate from } \\
\text { glass utensils }\end{array}$ & $\begin{array}{l}7 \\
3\end{array}$ & $\begin{array}{l}16 \cdot 0-65 \cdot 4 \\
12 \cdot 8-31 \cdot 4\end{array}$ & $\overline{-}$ & $\begin{array}{l}\text { Solid residue } \\
\text { Made experi- } \\
\text { mentally }\end{array}$ \\
\hline
\end{tabular}

${ }^{1}$ Both the indigenous distillate (4) and the experimental distillate (6) used the same beer (3)

The local water supply was tested and has a negligible metal content when compared to that in the spirit (Table IV).

It is clear from these results that the metal content arises not, after all, in the distilling but is present both in the initial brewing and in the spirit. In the brewing stage it is possible that yeast accumulates zinc ions dissolved from the walls of the container by the acid from fermentation. This metallo-organic compound was shown to distil at a relatively low temperature (Upadhyay, 1967).

\section{POSSIBLE ASSOCIATIONS WITH CARCINOGENESIS}

This geographical survey has drawn attention to a spatial association of disease and drinking custom. A concentration of metallic zinc in kachasu far above the safe limit of $5 \mathrm{mg} / 1$. in drinking water recommended by WHO has been demonstrated. This contamination cannot, however, be proved to be the cause of disease (Hill, 1965). In fact the effects on the human body of high concentrations of zinc taken in alcohol at irregular intervals are not known.

Zinc has been suggested as a causative agent for stomach cancer in Japan (Hirayama, 1962) and in England (Stocks and Davies, 1964) but zinc has been dismissed by Oëttlé (1962) as 'unlikely to have any bearing on oesophagus cancer'.

If contamination with zinc in indigenous spirits is proved to be irrelevant to carcinogenesis the geographical association between cancer and spirit drinking may be caused by some other constituent. Walters and McLean (1968) in London and Upadhyay (1968) in Lusaka have identified a nitrosaminelike substance in several samples of kachasu by polarograph and thin-layer chromatographicanalysis. The relevance of zinc may therefore lie merely in the formative stages of the nitrosamine compound. How this compound gets into the alcoholic drinks and how widespread is its occurrence in drinking spirits has still to be demonstrated.

\section{EPIDEMIOLOGY}

A satisfactory hypothesis for the pathogenesis of oesophageal carcinoma has certain observations to explain (Brit. med. J., Editorial, 1966). A marked increase in gross numbers of cases of this cancer has been reported (Ahmed, 1966; Oëttlé, 1962b) and males far outnumber females. It is suggested that the increase could reflect the replacement of indigenoustype clay utensils with metallic vessels and tubes which have become increasingly available in rural Africa in the last 20 years. In many tribes heavy drinking of spirits is particularly a male prerogative.

Since cases of oesophageal cancer are also reported in continents, countries, and social systems other than Africa, it cannot be claimed that contaminated alcohol is the carcinogen. It may be that this observation is a step towards recognizing one among many possible causes. 
The basic medical data generously supplied by all resident medical officers throughout the survey area have been invaluable and this paper would have been impossible without their help.

The valuable cooperation of Fr C. Reilly, PhD, SJ, lecturer in botany, University of Zambia, who carried out the spectrophotometric analyses, is most gratefully acknowledged. Chartered Exploration Corporation also kindly carried out sample spectrophotometric analyses and confirmed the results tabulated. Dr Walters of the British Food Manufacturers Industrial Research Association kindly made the nitrosamine analyses.

The method of surveying disease is acknowledged to Professor P. E. S. Palmer and the correlation calculations were carried out at the Department of Computer Sciences, University of the Witwatersrand.

Mr G. H. Adika, AIST, chief technician in Geography, University of Zambia, drew the maps, and a research grant from the University of Zambia has financed this inquiry.

\section{REFERENCES}

Ahmed, N. (1966). Geographical incidence of oesophageal cancer in West Kenya. E. Afr. med. J., 43, 235-248.

Brit. med. J., 2, 718-719 (Editorial). (1966). Oesophageal cancer.

Burrell, R. J. W. (1962). Esophageal cancer among Bantu in the Transkei. J. nat. Cancer Inst., 28, 495-514.
—- Roach, W. A., and Shadwell, A. (1966). Esophageal cancer in the Bantu of the Transkei associated with mineral deficiency in garden plants. Ibid, 36, 201-209.

Doll, R. (1967). Prevention of Cancer: Pointers from Epidemiology. Nuffield Provincial Hospitals Trust, London.

Hill, A. B. (1965). The environment and disease: association or causation? Proc. roy Soc. Med., 58, 295-300.

Hirayama, T. (1962). Personal communication quoted by Oettlé in $S$. Afr. Cancer. Bull., 6, 114.

McGlashan, N. D. (1967). Zinc and oesophageal cancer. Lancet, $1,578$.

-, Walters, C. L., and McLean, A. E. M. (1968). 'Ibid, 2, 1017.

Oett!é, A. G. (1962a). Cancer and environmental influences. S. Afr. Cancer Bull., 6, 110-124.

(1963a). The frequency of oesophageal cancer among the Bantu attending hospitals. Med. Proc., 9, 78.

- (1963b). Regional variations in the frequency of Bantu oesophageal cancer cases admitted to hospitals in South Africa. S. Afr. med. J., 37, 434-439.

- (1964). Cancer in Africa, especially in regions South of the Sahara. J. nat. Cancer Inst., 33, 383-439.

Palmer, P. E. S. (1963). Unpublished lecture 'Geographical Pathology' at the South African Institute for Medical Research.

(1967). Personal communication.

Steiner, P. E. (1954). Cancer, Race and Geography. Williams and Wilkins, Baltimore.

Stocks, P., and Davies, R. I. (1964). Zinc and copper content of soils associated with the incidence of cancer of the stomach and other organs. Brit. J. Cancer, 18, 14-24.

Upadhyay, J. (1967). Personal communication.

(1968). Personal communication.

Zambia (Northern Rhodesia) (1963). Report of the 1963 census of Africans in Northern Rhodesia. Government Printer, Lusaka. 